\title{
Paleocards: Redesign de jogo de tabuleiro educativo para ensino de Paleontologia
}

\author{
Paleocards: Redesign of educational board game for Paleontology teaching
}

SILVA, Pablo Joevalner Bastos da; Mestrando; Centro Universitário Teresa D’Ávila (UNIFATEA)

pablojbast@gmail.com

MOTA, Darwin Rodrigues; Mestre; Centro Universitário Teresa D’Ávila (UNIFATEA)

darwinrmota@gmail.com

SANTOS, Ricardo Mendonça Neves dos; Doutor; Centro Universitário Teresa D’Ávila (UNIFATEA)

ricfatea@gmail.com

\section{Resumo}

Este artigo apresenta o resultado de um projeto de graduação sobre o processo de redesign gráfico de um jogo de tabuleiro educativo utilizado para ensino de Paleontologia em cursos de ensino superior. Com o objetivo de solucionar o problema de efetividade da versão anterior do jogo, esta pesquisa buscou propor uma solução que respeitasse a mecânica e a ludicidade criadas no projeto original, bem como oferecer um produto visualmente elegante e eficiente. Para isso, foram realizadas pesquisas de fundamentação teórica sobre jogos, inserção do Design no processo de desenvolvimento e por fim, curadoria do material didático a ser inserido. Ao final, são apresentados o modelo físico desenvolvido e as considerações finais e perspectivas de trabalhos futuros.

Palavras Chave: Design gráfico; Paleontologia; Jogos educativos.

\begin{abstract}
This article presents the results of a graduation project on the process of graphic redesign of an educational board game used for teaching Paleontology in higher education courses. With the objective of solving the problem of effectiveness of the previous version of the game, this research sought to propose a solution that respects the mechanics and playfulness created in the original design, as well as offer a visually elegant and efficient product. For this, researches were carried out on theoretical foundations on games, insertion of Design in the development process and, finally, curation of didactic material to be inserted. At the end, the developed physical model and the final considerations and future work perspectives are presented.
\end{abstract}

Keywords: Graphic design; Paleontology; Educational games. 


\section{Introdução}

Um dos grandes desafios enfrentados pela educação desde sempre, é conseguir manter a atenção e despertar o interesse dos alunos pelas aulas e pelo próprio conhecimento em si. As aulas teóricas e os trabalhos práticos parecem que estão pouco a pouco entediando os estudantes e fazendo com que eles sintam-se desmotivados, o que pode retardar o processo de aprendizado ou ainda causar evasões de cursos. Com grande parte das informações e conhecimentos podendo ser acessados por meios mais fáceis e eficientes, a sociedade avança mais rapidamente do que jamais visto em outrora. Resultado disso, foi o fato de que escolas e professores precisaram também se adaptar, criando novos métodos e inovações para serem adicionados às práticas pedagógicas e, por consequência, modificar o relacionamento com os alunos de forma geral. A busca de alternativas aos métodos educacionais tradicionais e consolidados já é uma demanda visível e necessária para o desenvolvimento acadêmico nestes novos tempos. Portanto, a formação de indivíduos ativos, críticos e especializados está diretamente ligada à procura, desenvolvimento e domínio de novas técnicas e ferramentas pedagógicas. Neste sentido, a educação em constante transformação, e portanto, ainda mais complexa do que parecia antes, como aponta Moran (2004): a educação está saindo dos ambientes físicos das salas de aula, transformando o professor em um agente moderador e facilitador da aprendizagem e ainda, promovendo o aprendizado de forma mais coletiva com múltiplas fontes de informação.

Segundo Mendonça (s.d.), as aulas de várias disciplinas dos cursos de Biologia nos cursos superiores apresentam carga significativa de conteúdo teórico devido a elevada complexidade e abrangência de determinados temas. $O$ autor complementa dizendo que, mais especificamente no caso da Paleontologia, há um vasto conteúdo a ser ministrado nas aulas, porém o tempo hábil disponibilizado pelas Instituições de Ensino Superior para transmitir o conteúdo torna a tarefa do professor muitas vezes quase impossível. Por fim, Mendonça (s.d.) conclui que o ensino da Paleontologia age como base fundamental para o entendimento de outras disciplinas como a Zoologia, Botânica, Biogeografia e Evolução. Isso acarreta na formação de profissionais com conhecimento limitado e pouco profundo dos temas acima citados, o que mais tarde por determinadas exigências, forçariam os profissionais a estudarem novamente temas que já deveriam ter sido aprendidos. Diante deste contexto, a utilização de estratégias e ferramentas alternativas como os jogos educacionais torna-se um recurso importante para o decorrer das aulas. A aplicação de atividades ou recursos alternativos surge como elemento para consolidar os conhecimentos adquiridos em aula e ainda, como gatilho para despertar a curiosidade e interesse dos estudantes a cerca de um tema tão importante para o ensino da Biologia.

Tendo como público-alvo as turmas dos cursos de Biologia de Ensino Superior, 'Paleocards' foi desenvolvido como ferramenta de aprendizado e avaliação dos alunos na disciplina de Paleontologia. O jogo tem como objetivo facilitar a assimilação do conteúdo por meio de trabalho em equipe e mediação do processo pelo professor. Contudo, a versão atual sofre de problemas de efetividade quando utilizado e o processo de aprendizado não se completa; o que faz com que o jogo perca seu valor pedagógico. Portanto, como objetivos deste trabalho estão o desenvolvimento um novo projeto gráfico para o jogo educativo 'Paleocards' e a inserção de novos conteúdos didáticos, de modo a expandir o número de pontos a serem abordados. A partir disso, a solução projetada deve oferecer um layout eficiente, capaz de suprir a debilidade apresentada de forma a reinserir 'Paleocards' em sala de aula com uma proposta adequada à sua função. 


\section{Metodologia}

Partindo do princípio de que a equipe de desenvolvimento deste trabalho é multidisciplinar, há a necessidade de aplicar uma metodologia capaz de permitir a interação e integração de todos os conhecimentos envolvidos. Portanto, foi adotado como ferramenta metodológica principal o Design Thinking, desenvolvida e consagrada pela consultoria americana em design e inovação IDEO; sendo esta uma metodologia que permite a multidisciplinariedade do grupo de projetistas. Em essência o Design Thinking opera em duas etapas, segundo Brown (2010): 1) Fase divergente: etapa de coleta e interpretação de dados sobre o problema e, em seguida, o início da formulação de possíveis soluções. 2) Fase Convergente: etapa de síntese da pesquisa previamente realizada e em seguida, realização de processo de seleção das melhores ideias e propostas.

Na fase divergente, foram realizadas pesquisas bibliográficas no âmbito da compreensão dos temas relacionados aos jogos de tabuleiro, de forma a compreender suas particularidades e suas vantagens e oportunidades de aplicação como ferramenta pedagógica em salas de aula. Foram também realizadas pesquisas sobre o campo da Paleontologia para a produção do conteúdo didático; de forma a coletar informações e referências de imagens, texto e elaboração de arcabouço estilístico para o desenvolvimento de novo projeto gráfico. Por fim, foi realizada uma análise de produtos similares para complementar a pesquisa bibliográfica e alimentar o processo de criação do novo projeto gráfico do jogo.

No que diz respeito à fase convergente, foi realizado um processo de curadoria do conteúdo didático a ser inserido, de forma a inserir os temas que fossem mais interessantes ao processo de aprendizado. Foram realizados também estudos sobre design gráfico para determinar a melhor solução para o layout, selecionando as cores, estilos gráficos e malha construtiva mais adequada para a proposta do jogo. Ao final deste processo, fora desenvolvido um modelo físico da proposta final a ser avaliada, contendo baralho de cartas, tabuleiro, peões, manual do jogo e embalagem para transporte.

\section{Jogos e suas vantagens como ferramenta de ensino}

$\mathrm{O}$ ato de jogar tem sido uma constante através do tempo na história da humanidade, sejam os jogos feitos de gravetos, pedras e ossos, ou de avançada tecnologia de computação gráfica. Por muito tempo o conceito de jogo ficou atrelado à ideia de entretenimento, diversão e passatempo para crianças, jovens e adultos. Basta fazer um pouco de esforço e logo nomes como Banco Imobiliário, Detetive, Jogo da Vida, Gamão, Damas ou Xadrez saltam à mente, trazendo boas lembranças e momentos especiais. Contudo, os jogos tem um efeito muito mais profundo do que apenas entreter e muitas vezes é imperceptível: fazer com que sejam aprendidas novos conhecimentos. Crawford (1982) aponta que o principal motivo de um jogo é justamente para ensinar algo e que se utilizar dele como ferramenta educativa não é característica somente restrita aos seres humanos:

Os jogos são, assim, o veículo mais antigo e consagrado para a educação. Eles são a tecnologia educacional original, o natural, tendo recebido o selo de aprovação da seleção natural. Nós não vemos leoas ensinando os filhotes no quadro-negro; não vemos leões experientes escrevendo suas memórias para a posteridade. À luz disto, a pergunta: "Podem os jogos ter valor educativo?" torna-se absurda. Não são jogos, mas as escolas que são a noção 
ultramoderna, a nova tendência, o infrator da tradição. Jogar é uma função educativa vital para qualquer criatura capaz de aprender. (CRAWFORD, 1982, p. 15, tradução nossa).

Os jogos com propósitos educacionais são em essência, ferramentas para ensinar determinado assunto enquanto os jogadores estão jogando. Também chamados de jogos sérios (serious games), os jogos educacionais "permitem apresentar novas situações, discutir soluções, construir conhecimentos e treinar atividades particulares" (SOARES, 2012). Em suma, o princípio por trás da existência dos jogos sérios é inserir o jogador em determinada problemática e fazer com que ele se utilize de seus conhecimentos prévios para resolver determinados problemas e situações. Pode-se elencar as seguintes vantagens da aplicação de jogos com propósitos educacionais: 1). Em primeira instância há o desenvolvimento das habilidades cognitivas e sociais dos indivíduos, de forma que $o$ ato de jogar faz com que os participantes interajam entre si e troquem informações e conhecimentos. Segundo Antunes (2002) o uso de jogos educacionais permite um maior desenvolvimento de áreas como cognição, linguística, afetiva e motora, além de expandir o pensamento crítico e permitir a cooperação, sociabilização e promover a responsabilidade entre os jogadores. 2). A realização de simulações a partir de jogos é um ponto forte a favor de sua utilização: simular certas situações ou cenários em uma situação real podem ser inviáveis por questões financeiras, logísticas ou de qualquer outra ordem. Esta característica é muito explorada em situações de treinamento em agências e empresas, por exemplo, para capacitarem seus colaboradores a lidarem com determinados problemas. 3). Inserção e fortalecimento do fator motivacional, sendo ele capaz de incentivar o estudante a pesquisar e a aprender mais sobre o assunto tratado. Abt (1974) aponta que planejar, jogar e analisar os jogos educativos motiva o jogador e a estudar o conteúdo tratado no jogo. Sendo assim, o jogador sente-se motivado a procurar por mais referências de estudo, pensar soluções diferentes para os problemas já apresentados e por fim, avaliar as soluções por ele mesmo desenvolvidas.

No caso de uso de jogos especificamente voltados para a Paleontologia, Sobral \& Siqueira (2007) conseguiram produzir resultados satisfatórios no uso de jogos para ensino da história da vida na Terra em turmas de alunos do ensino fundamental. No mesmo ano, Andrade e Anelli (2007) apresentaram o "Trilhassauro" e seu complemento "Glossauro", um jogo de tabuleiro em que os jogadores devem cruzar a linha do tempo da Paleontologia desde a Origem da Terra até os dias atuais. Em experiência semelhante, Neves et al. (2008) foram capazes de alcançar sucesso em turmas de 3 e e 8 o anos do ensino fundamental no que tange a motivar os alunos com o tema da Paleontologia. Apesar de apresentar benefícios evidentes ao processo de aprendizado, a quantidade de jogos educacionais de disponíveis ainda é pequena e por isso, a aplicação em salas de aula e a documentação sobre os resultados obtidos nas experiências ainda é modesta e carece de propostas bem construídas e adaptadas para os diferentes públicos.

\section{Paleocards}

O jogo de tabuleiro Paleocards foi criado e desenvolvido para utilização em aulas da disciplina de Paleontologia no curso de Biologia de instituições de ensino superior. Com o intuito de instigar os alunos a aprenderem o conteúdo teórico da matéria de forma mais fácil e prática, o jogo também serviria como método de avaliação do progresso de aprendizado dos alunos. $\mathrm{O}$ criador, além de ter selecionado todo o conteúdo didático a ser inserido, foi o responsável por criar e confeccionar as cartas e o tabuleiro. 
Criado para ser jogado em equipes, 'Paleocards' estabelece que os grupos devem competir entre si em uma disputa de perguntas e respostas sobre Paleontologia. $\mathrm{O}$ jogo se divide em três etapas: a primeira etapa é um teste prévio em forma de dissertação de um texto sobre a história dos organismos no planeta; a segunda etapa é a aplicação do jogo propriamente dito; e a terceira etapa é uma nova avaliação dada pelo professor para efeito comparativo sobre o desempenho dos alunos antes e depois da aplicação de 'Paleocards'. O professor é mediador da partida e a qualquer momento pode intervir, corrigindo ou complementando as informações utilizadas tanto nas perguntas quanto nas respostas dos jogadores. Em sua versão original, há um baralho de 13 cartas (Figura 1), 9 cartas fazem a representação dos períodos geológicos das Eras Paleozoica, Mesozoica e Cenozoica; já as 4 cartas restantes, denominadas "cartas coringa", exibem informações sobre determinado tema específico de grande importância para a Paleontologia. Os elementos e informações dispostos na parte frontal da carta seguem uma lógica de construção, sendo descritas na Tabela 1.

Figura 1 - Frente e verso das cartas do projeto original de 'Paleocards'
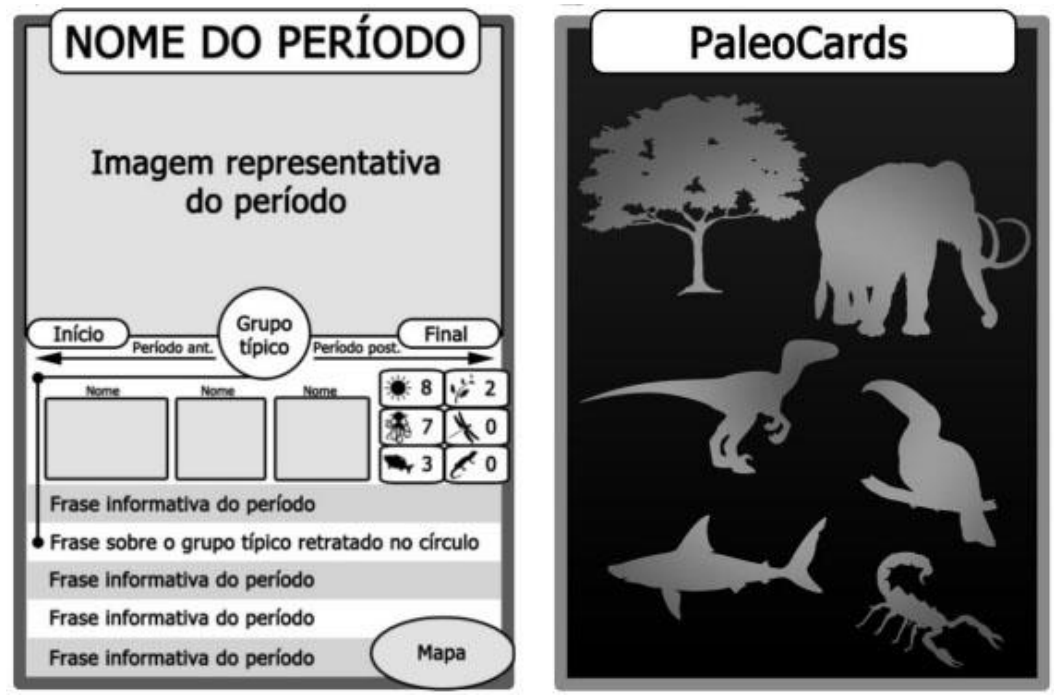

Fonte: Mendonça (s.d.)

Tabela 1 - Organização de informações e descrição dos itens das cartas

\begin{tabular}{|l|l|l|}
\hline Informação & Exemplo & Descrição \\
\hline & Cor verde & $\begin{array}{l}\text { Borda da carta } \\
\text { Vermelho = Paleozoico } \\
\text { Verde = Mesozoico } \\
\text { Azul = Cenozoico } \\
\text { Amarelo = Cartas coringa }\end{array}$ \\
\hline NOME DO PERÍODO & Cretáceo & Nome do Período geológico \\
\hline
\end{tabular}




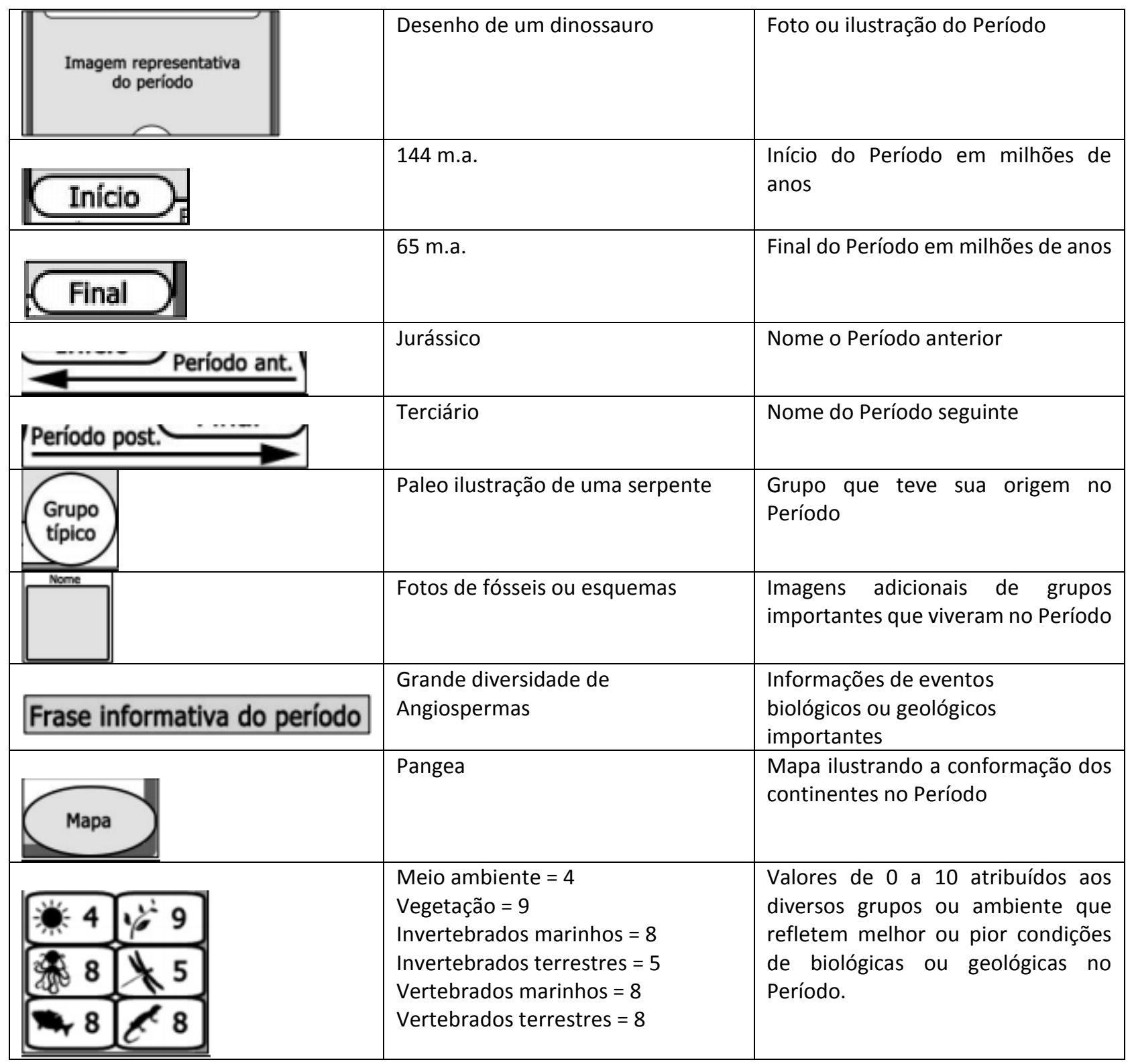

Fonte: Adaptado de Mendonça (s.d.)

No tabuleiro (Figura 2) em forma de ziguezague, os jogadores devem cruzar por várias casas que identificam uma tarefa ser cumprida, punição ou um prêmio a ser recebido naquela rodada. $\mathrm{Na}$ versão inicial do jogo, o tabuleiro pode ser tanto impresso em folha tamanho A3 ou projetada em tela branca com uso de um aparelho projetor (Datashow). De acordo com o que fora estabelecido como mecânica de jogo, as imagens e seus significados no tabuleiro são estes:

- Direta (imagem do paleontólogo): o professor sorteará uma carta e fará uma pergunta direta ao grupo que não terá acesso ao seu conteúdo, que se acertar terá o direito de jogar novamente;

- Carta: o grupo sorteará uma carta, tendo acesso ao seu conteúdo, e deverá responder uma pergunta feita pelo professor; 
- Desafio: o grupo sorteará uma carta, tendo que formular uma pergunta para que o grupo seguinte responda. Se o grupo desafiado acertar, eles andam o valor de casas sorteado no dado, caso erre, o grupo que formulou a pergunta anda;

- Perigo: nas casas com a imagem de um crânio de dinossauro o grupo é penalizado e deverá voltar duas casas retornando à casa "Direta";

- Evolução: nas casas com a imagem do fóssil Archaeopteryx, o grupo ganha o direito de avançar 4 casas;

- Meteoro: nas casas com a imagem de um meteoro em queda o grupo perde a vez de jogar na próxima rodada.

Figura 2 - Tabuleiro do projeto original de 'Paleocards'
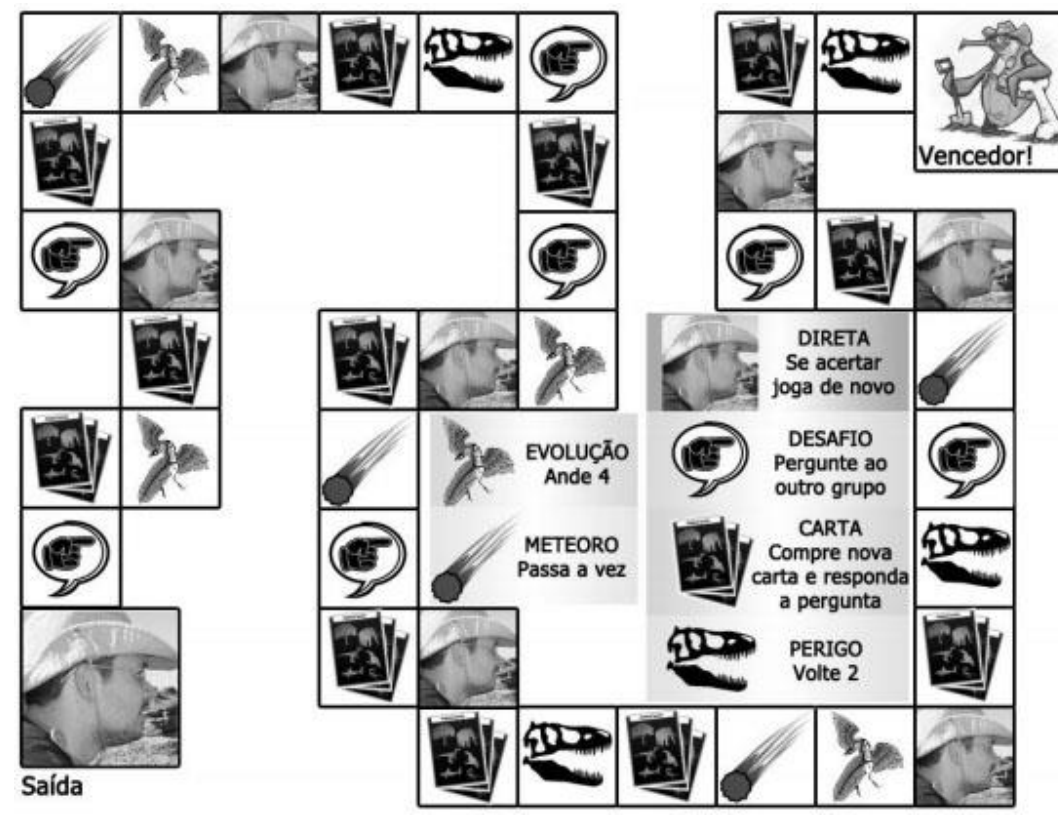

Fonte - Mendonça (s.d.)

\section{Definição e Desenvolvimento}

Segundo o processo metodológico do Design Thinking, após o término da pesquisa de informações, há a etapa de análise e alinhamento das informações teóricas coletadas com os objetivos a serem atingidos. A partir disso, definiu-se como pontos importantes e restrições para o desenvolvimento do novo projeto gráfico do jogo: 1) a necessidade de um layout simplificado nas cartas para melhor compreensão das informações; 2) a inserção de novos conteúdos didáticos de forma a expandir a quantidade de assuntos tratados durante a aplicação do jogo; 3) construir um estilo gráfico que condissesse com a temática da Paleontologia, de forma a promover uma relação de maior fidelidade com o tema e despertar o interesse dos jogadores; e por fim 4) preservação da mecânica do jogo, de forma a funcionar com os mesmos princípios e regras da versão original.

Para o início do desenvolvimento de possíveis propostas para "Paleocards", foi conduzida uma pesquisa de produtos similares para analisar as soluções gráficas por eles implementadas, de 
forma a fornecer referências e pistas de como produzir um modelo para este projeto. Nesse processo foram analisados temas como seleção e aplicação de cores, imagens e ilustrações, tipografia e estrutura de composição gráfica. Foram analisados também jogos que possuem as mesmas mecânicas de jogo, para que a proposta a ser desenvolvida obedeça certas características em comum entre os dois jogos e que a jogabilidade não seja comprometida. A pesquisa de similares também foi aplicada no âmbito da definição da estética voltada para a Paleontologia, de forma a buscar diversos produtos voltados para o tema e captar imagens, símbolos, cores e expressões características do tema. A partir da realização dessa etapa, se estabelece uma base sólida para a criação de um projeto gráfico adaptado às demandas e necessidades de "Paleocards" e consequentemente, de seus futuros usuários.

\subsection{Proposta de solução}

Com o término da fase de análise e alinhamento das informações coletadas, inicia-se o processo de curadoria do conteúdo didático do jogo e em seguida, o desenvolvimento do novo projeto gráfico de "Paleocards".

No quesito curadoria e seleção do conteúdo didático, o resultado foi o aumento do número de cartas do baralho de 'Paleocards' de 13 cartas (na versão original) para 54 cartas (nova versão), sendo elas divididas em 40 cartas de espécimes e 14 de períodos geológicos. Desta forma, pôde-se direcionar e simplificar o processo de aprendizado selecionando os conceitos mais importantes para serem estudados pelos alunos. Para as cartas de espécimes foram selecionadas as seguintes informações:

- Nome científico;

- Idade do fóssil;

- Local encontrado;

- Grupo taxonômico;

- Tamanho;

- Alimentação;

- Hábitat;

- Imagem ilustrativa do espécime.

Para as cartas de períodos geológicos foram selecionadas as seguintes informações:

- Nome do período;

- Início e término do período em anos;

- 4 características importantes do período.

Para o levantamento dos dados apresentados nas cartas foram utilizadas obras de referência na área de Paleontologia (MENDES, 1988; LIMA, 1989; CARTELLE,1994; FARIÑA; VIZCAÍNO, 1995; 
KELLNER et al., 1999; BARRETT, 2002; MOREIRA, 2002; CARVALHO, 2004; ANELLI, 2010). Os espécimes, períodos geológicos e seus respectivos dados foram selecionadas por critério de importância e/ou relevância para os estudos de Paleontolgia. As imagens dos espécimes que ilustram as cartas de "Paleocards" também foram baseadas em modelos utilizados e produzidos por literatura especializada, mantendo portanto a fidelidade e o compromisso com a produção de conteúdo didático baseado em referências já consagradas.

No que se refere à definição do estilo gráfico, foram consideradas os seguintes pontos: devido a elevada necessidade de compreensão exigida pelo jogo, faz-se necessário o uso de elementos gráficos simples e não sobrecarregar as cartas com excesso de informações e imagens. Portanto foi adotado um estilo minimalista de composição gráfica, tanto no que se refere à estrutura de disposição das informações quanto nas ilustrações contidas nos componentes do jogo. Isso permitiria que todos os elementos dispostos nas cartas, tabuleiro, manual e embalagem fosse mais facilmente compreendido além de oferecer uma estética elegante e moderna.

Afim de que o jogo fosse atrativo e que despertasse o interesse do público, era necessário adotar como estilo gráfico símbolos, cores e tipografia que remetessem ao universo da Paleontologia. Dessa forma foram selecionadas cores essencialmente terrosas (Figura 3), de forma a remeter ao processo de procura e escavação de fósseis.

Figura 3 - Paleta de cores da nova versão de "Paleocards"

\begin{tabular}{|l|l|}
\hline C: 0 & C: 0 \\
M: 100 & M: 73 \\
Y: 96 & Y: 100 \\
K: 28 & K: 80 \\
C: & C: \\
M: 33 & M: 47 \\
Y: 67 & Y: 100 \\
K: 0 & K: 8 \\
\hline
\end{tabular}

Fonte: Autores (2015)

Como proposta final, foram desenvolvidas soluções de modo a abarcar todo o projeto gráfico do jogo, reformulando a estrutura das cartas (Figura 4) e do tabuleiro (Figura 5), criação de um manual do jogo (Figura 6) e confecção de uma embalagem (Figura 6). As cartas foram os componentes que mais receberam modificações, tendo sua estrutura completamente modificada em relação à sua versão anterior. $O$ tabuleiro recebeu somente um novo projeto gráfico, de maneira a respeitar o objetivo de manter a mecânica original do jogo. A adição do manual possibilita o melhor aprendizado para os jogadores sobre o jogo, regras e componentes. Por fim, a confecção da embalagem permite o transporte seguro e organização dos elementos do jogo. O projeto se conclui com a produção do modelo físico (Figura 7) para aplicação em sala de aula de forma a substituir a versão anterior. 
Figura 4 - Exemplos do novo projeto das cartas: espécimes, períodos geológicos e o verso padrão.
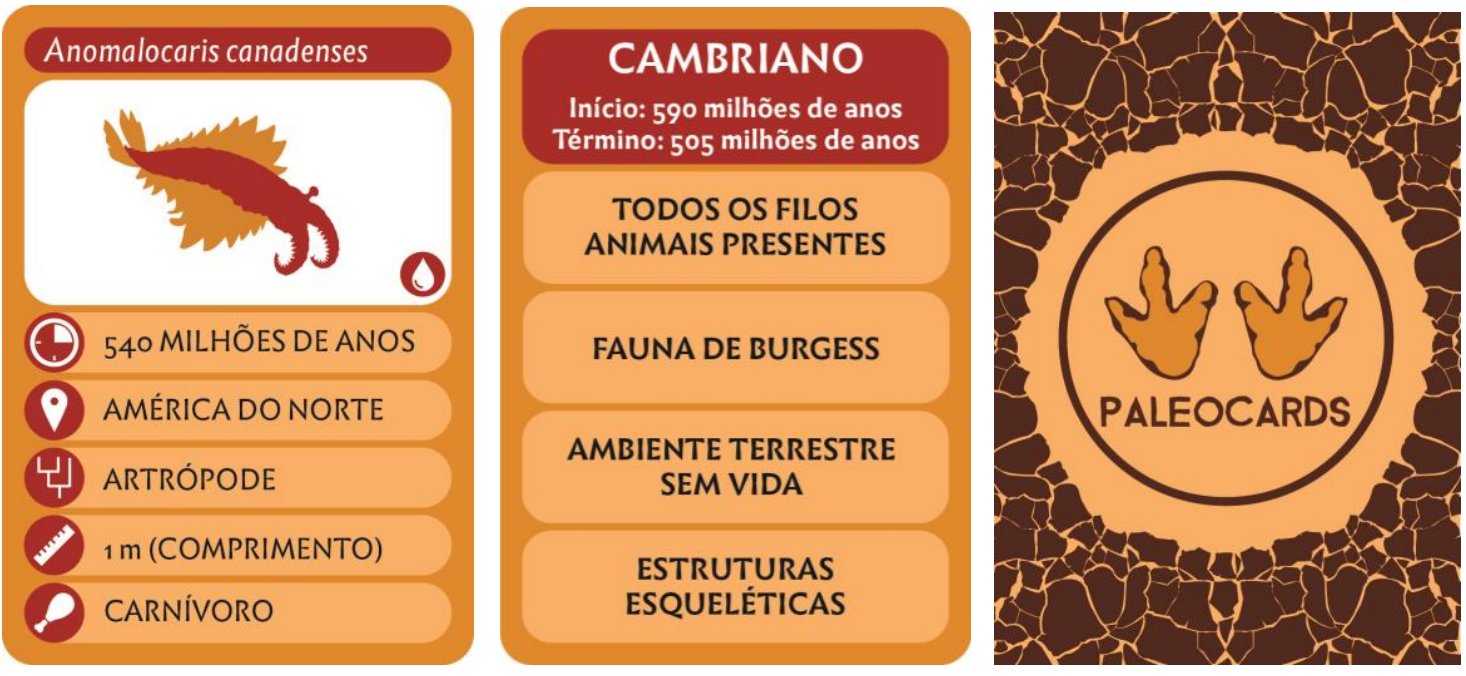

Fonte: Autores (2015)

Figura 5 - Solução final para o tabuleiro.

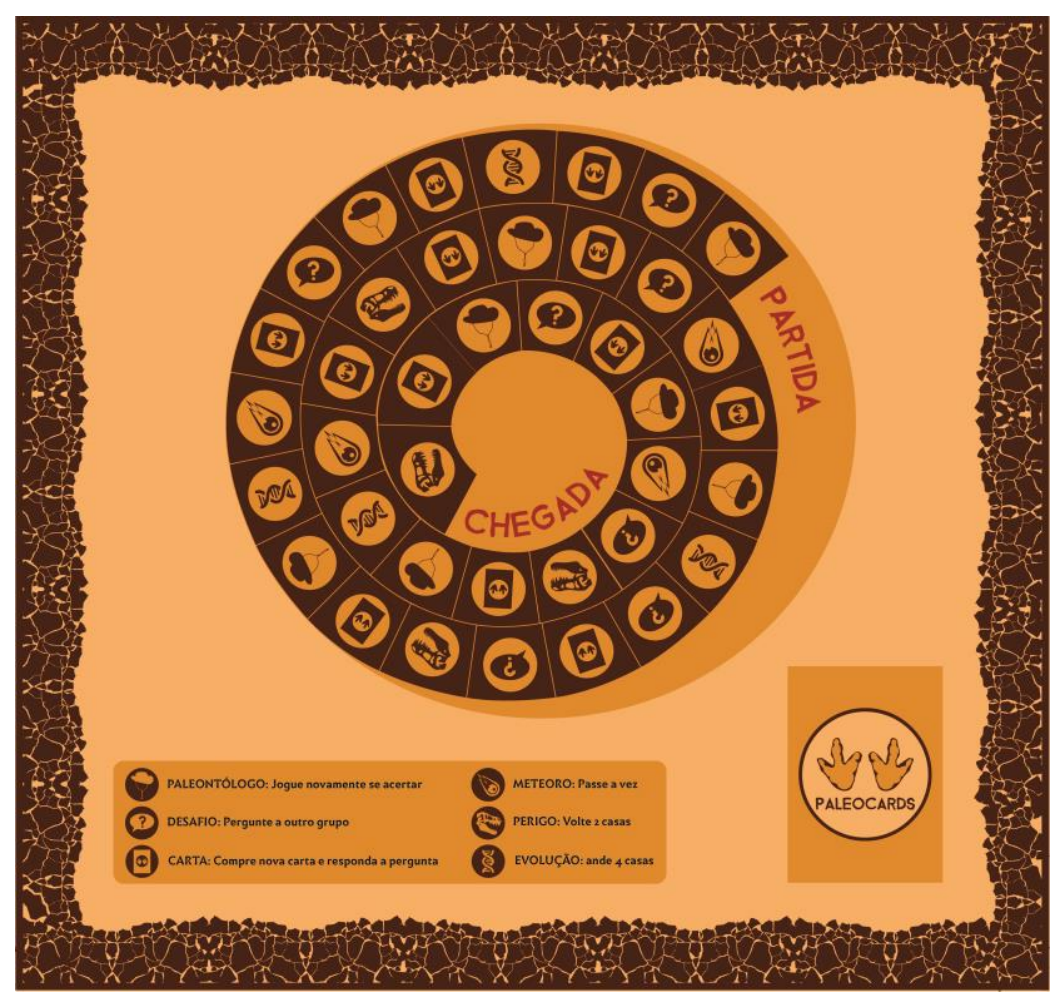

Fonte: Autores (2015) 
Figura 6 - Capa do Manual do Jogo e exemplo de página do manual.

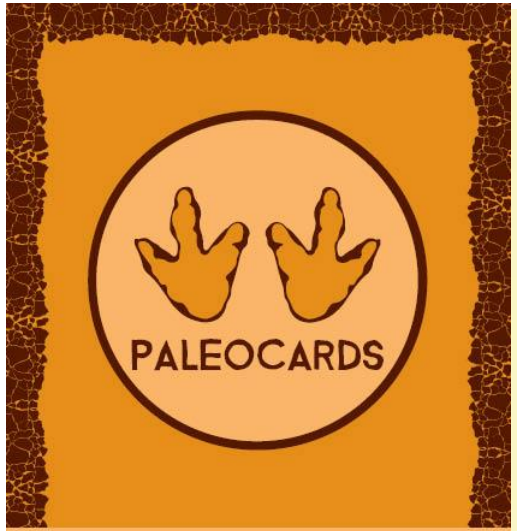

MANUAL DO JOGO

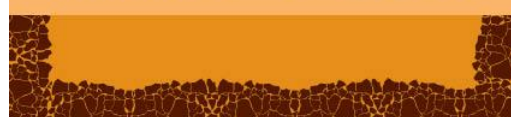

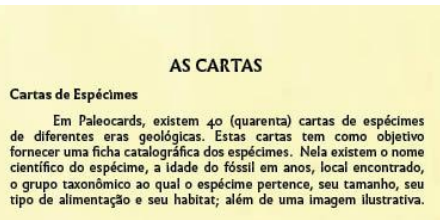

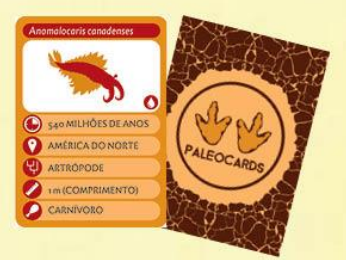

Todo o conteúdo didático usado na construçăo das cartas fol Pevantado de acordo com obro

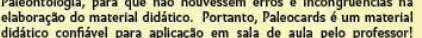

Fonte: Autores (2015

Figura 7 - Layout final da embalagem do jogo.

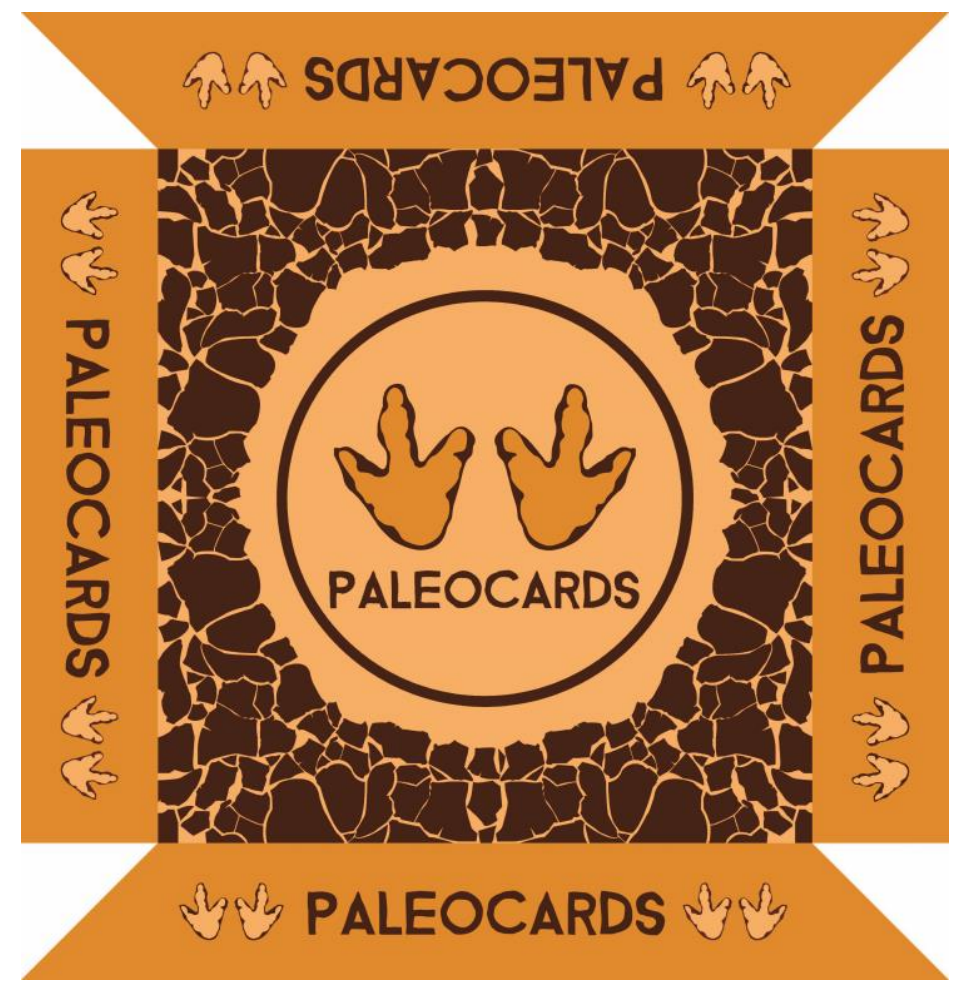

Fonte: Autores (2015) 
Figura 7 - Modelo físico completo.

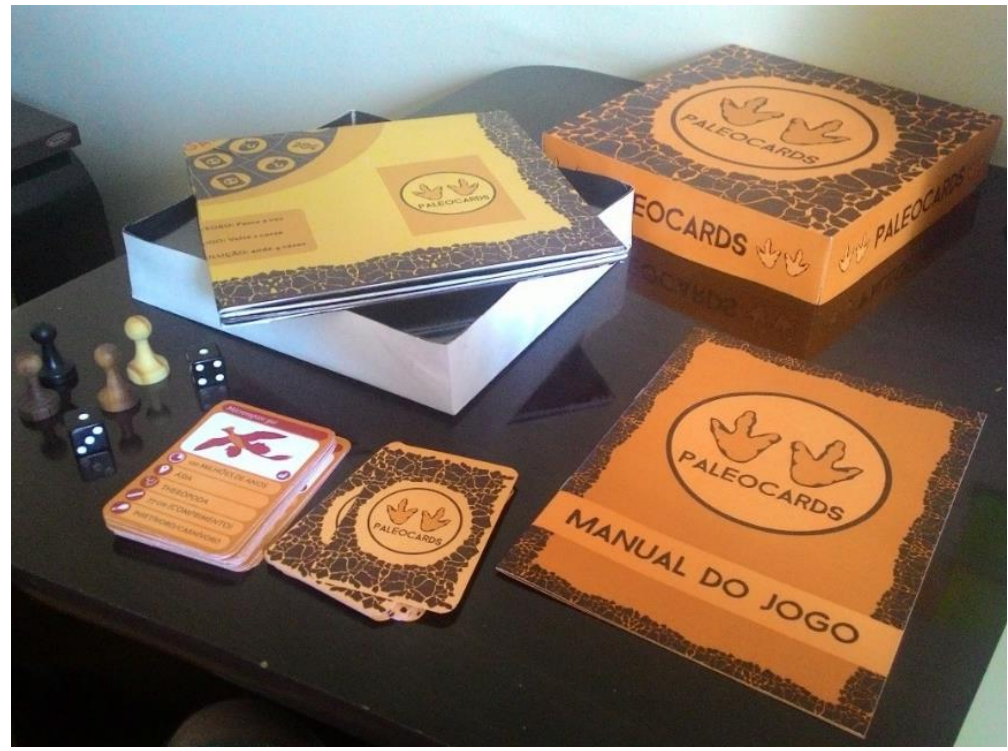

Fonte: Autores (2015).

\section{Conclusão}

Após a realização da pesquisa, é possível dizer que os jogos são excelentes meios para dar oportunidade de crescimento intelectual e social em pessoas de todas as idades, fazendo com que se sintam motivados e curiosos por meio da ludicidade. Atividades como estas fazem com que os estudantes se disponham voluntariamente a aprender jogando sem muitas vezes perceber que está adquirindo conteúdo intelectual. Conteúdos complexos são muitas vezes encarados como grandes obstáculos e podem gerar uma série de dificuldades que atrapalham o desenvolvimento e afetam a própria autoestima dos estudantes. Por meio de desenvolvimento de propostas lúdicas como esta, é possível transmitir e explicar esses conteúdos complexos de forma mais palatável e aceitável. Fazse necessário ressaltar que apesar de serem facilitadores do aprendizado e servirem de auxílio ao professor, a aplicação de recursos como os jogos não garante a solução dos problemas de ensino. Contudo a utilização destas ferramentas e atividades lúdicas propõem alternativas e apresentam possibilidades para a construção e propagação do conhecimento.

Até o presente momento, a nova versão de 'Paleocards' ainda não foi usada em testes. Desta forma não foi possível avaliação ou coleta de dados para determinar de que forma o jogo interfere no processo de aprendizado, seja de forma positiva ou negativa em comparação com sua versão anterior. Entretanto, considerando que há a necessidade da implantação de novas métodos e ferramentas para ensino de discentes de modo a estimular o aprendizado e desenvolvimento, 'Paleocards' se mostra como uma proposta interessante para aplicação. Para novos trabalhos, há a perspectiva de transformar a proposta do jogo físico em um produto digital, para desta forma atingir um maior número de estudantes e oferecer outra possibilidade de uso para 'Paleocards. 


\section{Referências}

ABT, C. Jogos simulados: estratégia e tomada de decisão. Rio de Janeiro: José Olympio, 1974.

ANDRADE, F; ANELLI, L. Trilhassauro. São Paulo: Ciranda Cultural, 2007. 16p.

ANELLI, L. E. O guia completo dos dinossauros do Brasil. São Paulo: Editora Peirópolis, 2010.

ANTUNES, C. 2002. Jogos para a estimulação das múltiplas inteligências. 11ạ ed. Petrópolis - RJ: Editora Vozes.

BARRETT, P. Dinossauros: uma história natural. São Paulo: Martins Fontes, 2002.

BROWN, T. Design Thinking - Uma Metodologia Poderosa para Decretar o Fim das Velhas Ideias. São Paulo: Elsevier, 2010, 272 p.

CARTELLE, C. Tempo passado: mamíferos do Pleistoceno em Minas Gerais. Belo Horizonte: Editora Palco, 1994.

CARVALHO, I. DE S. (ED.). Paleontologia. 2a ed. Rio de Janeiro, 2004.

CRAWFORD, C. The Art of Computer Game Design. 1982. 81 p. Disponível em: <http://wwwrohan.sdsu.edu/ stewart/cs583/ACGD_ArtComputerGameDesign_ChrisCrawford_1982.pdf>.

Acesso em: 01/04/2015.

FARIÑA, R. A.; VIZCAÍNO, S. F. Hace sólo diez mil años: donde se trata de cómo era la gran fauna que habitó América del Sur ante de los indios.6aed.Montevideo: Editorial Fin de Siglo, 1995.

KELLNER, A. W. A.; SCHWANKE, C.; CAMPOS, D. DE A. 0 Brasil no tempo dos dinossauros. Rio de Janeiro: Museu Nacional, 1999.

LIMA, M. R. DE. Fósseis do Brasil. São Paulo: Editora da Universidade de São Paulo, 1989.

MENDES, J. DE C. Paleontologia básica. São Paulo: Editora da Universidade de São Paulo, 1988.

MENDONÇA, R. Paleocards: uma metodologia alternativa para aulas teóricas de Paleontologia na formação de professores. [S.I.]. [S.d.].

MORAN, J. M. Perspectivas (virtuais) para a educação. Mundo virtual, Cadernos Adenauer IV, no 6. Rio de Janeiro: Fundação Konrad Adenauer, abr, 2004, p. 31-45.

MOREIRA, L. E. A gênese (comentada) da humanidade. Goiânia: Editora da UCG, 2002.

NEVES, J. P.; CAMPOS, L. M. L.; SIMÕES, M. G. Jogos como recurso didático para o ensino de conceitos paleontológicos básicos aos estudantes do ensino fundamental. Terra Plural: UEPG, v. 2, n.1, p. 103-114, 2008.

SOARES, M. DOS S. Projetos de Jogos Educativos 2D de Aventura usando Lua. 2012. 63pg. Dissertação- Pontifícia Universidade Católica do Rio de Janeiro, Rio de Janeiro, 2012. 
SOBRAL, A.; SIQUEIRA, M. Jogos Educativos na Aprendizagem de Paleontologia do Ensino Fundamental. Anuário do Instituto de Geociências - UFRJ, v. 30, n. 1, p.213-214, 2007. 